\title{
Uniqueness of the Definite Article with Respect to Cognitive Frames
}

\author{
Ryo Oda
}

\begin{abstract}
It has often been argued in the relevant literature that the use of the singular definite article can be explained with the uniqueness theory, which postulates that the singular definite requires the existence of only one entity that meets the description. However, there are many instances of singular definites, which seem contrary to the uniqueness requirement, as illustrated by the hospital in the example "In Paris, I caught the measles and I went to the hospital to receive treatment." Some researchers have claimed that the use of such a singular definite cannot be adequately explained with the uniqueness theory. Others have argued that the hospital in this example refers not to a particular hospital in reality but to the unique role "hospital" within a "city" frame. This paper argues that the cognitive frame that supports the felicitous use of the definite the hospital in this example is not an inflexible "city" frame but a flexible "medical care" frame, which is evoked by the linguistic context and the situation of the utterance. The paper aims to explain the enigmatic use of singular definite descriptions in English, with special reference to cognitive frames, and to illustrate the affinity between the definites in configurational use and the definite associative anaphora.
\end{abstract}

\section{Previous research and problems encountered}

\subsection{Uniqueness}

This paper examines the use of the singular definite article in English ${ }^{1}$. The previous related literature has often argued that the use of the singular definite

1 At the outset of this study, we began with the analysis of articles in French and then extended our study to the use of articles in English. The uses of definite descriptions in English and in French are not entirely parallel. However, with regard to the use of a definite description without any unique referent explicitly introduced in the context that we will deal with in this paper, the definite descriptions in English and in French behave in an almost similar manner. Thus, the problems and 
article can be explained with the uniqueness theory ${ }^{2}$. According to this theory, the speaker uses the definite article when he/she supposes that his/her hearer can apply a unique referent to the definite description or can uniquely identify the referent (Russell 1905, Lambrecht 1994, Gundel, Hedberg \& Zacharski 1993, 2001). The comparison of examples (1) and (2) as well as the examination of example (3) will provide us a general view of this fundamental principle.

(1) Could you pass me the pen?

(2) Could you pass me a pen?

(3) It is not a solution, but the solution.

In example (1), the use of the singular definite article in the pen implies that there exists only one pen in the immediate situation and the hearer can identify this unique pen. In example (2), on the other hand, the use of the singular indefinite article implies that there can be more than one pen in the immediate situation. Similarly, in example (3), the singular indefinite in a solution presupposes that there can be more than one solution, whereas the singular definite in the solution indicates that this is the only solution. However, there are many instances where the use of the singular definite is contrary to the uniqueness requirement.

(4) Emma had a bad headache yesterday, and she went to buy some medicine at the pharmacy.

In example (4), suppose that there is more than one pharmacy in the city where Emma lives. The employment of the singular definite article in the pharmacy is quite appropriate, even though the interlocutor does not know exactly which pharmacy Emma went to. The uniqueness condition, thus, does not seem to be fulfilled here. In this paper, the pertinence of the uniqueness condition in instances such as those exemplified above will be addressed.

our analysis of these problems to be proposed herein with regard to definite descriptions in English will apply mostly to French definite descriptions. Because of space limitations, the discussion and data in this paper will be concerned exclusively with the use of articles in English.

2 Aside from the uniqueness theory, the following familiarity condition has been proposed in some previous literature: the referent of the definite description is familiar within the discourse (Christophersen 1939, Heim 1983). However, we will start off by assuming that the use of the singular definite description is predominantly governed by the uniqueness condition, and will not discuss here the validity of the familiarity theory. 


\subsection{Birner \& Ward (1994)}

Birner and Ward cite examples (5) and (6) to illustrate the validity of the uniqueness theory.

(5) Your 10:00 appointment - a Mr. Johnson - said he'd be late because he had to stop at the bank first. (Birner \& Ward 1994)

(6) As soon as my cousin arrived in Santiago, she broke her foot and had to spend a week in the hospital. (Ibid.)

(7) *While in Santiago, Bill broke his foot and was rushed to the big hospital. (Ibid. $)^{3}$

In example (5), it is obvious that there is more than one bank in the city, but the use of the singular definite article in the bank is appropriate even if the hearer does not know exactly which bank is being spoken about. Similarly, there must be several hospitals in Santiago in example (6), but the use of the singular definite in the hospital is adequate even if the hearer cannot identify the hospital in question. Singular definites of this nature do not have any obvious referent in the preceding context, either in the hearer's memory or in the immediate situation. Birner and Ward notice two points from these examples. First, such singular definites are used to refer to "locations" in general, the point which we do not agree with, as will be shown later. Second, this use of the singular definite is acceptable only if the intended referent is not relevantly differentiated from other referents denoted by the same noun phrase in the context. Thus, the modifier big attached to the hospital distinguishes the referent from the other hospitals in example (7), and this differentiation makes the expression the big hospital infelicitous, unless the hearer can identify this particular hospital. Because there is much evidence in support of their second viewpoint, we agree with it. However, Birner and Ward ${ }^{4}$ conclude that the uniqueness condition is not a necessary condition for the felicitous use of the definite article, because as examples (5) and (6) show, the intended referent is not always uniquely identifiable.

At this point, we would like to raise two questions: Does the use of such a singular definite really deny the validity of the uniqueness theory? Furthermore,

3 In this paper, the asterisk (*) indicates ungrammaticality or infelicity in the context.

4 Birner \& Ward (1994) maintain that familiarity is neither a necessary nor a sufficient condition for the felicitous use of the definite article. 
why is it that some singular definite descriptions, when being introduced in the context without a uniquely identifiable referent, can often refer to a location?

\subsection{Epstein (1999)}

Epstein (1999) adopts cognitive frames to analyze the definite article. According to him, when a noun phrase designates a role, it refers to a fixed property, but not to a particular individual.

(8) The President is elected every four years. (Epstein 1999)

(9) The President is giving a speech tonight. (Ibid.)

In example $(8)^{5}$, the noun phrase the President is most likely to be interpreted as the role that designates the property of "being President." Meanwhile, in example (9), the same noun phrase, the President, is most likely to be interpreted as the value that denotes the particular individual fulfilling the role of the President at the time of utterance; in the context of 1962, the value that satisfies the role of the President of the United States of America is John F. Kennedy; in 2013, it is Barack Obama. Following this idea, Epstein developed the theory that "definite descriptions frequently refer to roles representing stereotypical elements within cognitive frames." (Epstein 1999:126)

Birner and Ward also examined the concept of the cognitive frame while analyzing the singular definite; they arrived at the conclusion that the definite without an obvious antecedent (or a uniquely identifiable referent) cannot be explained with cognitive frames.

(10) The first thing we did upon arriving in Santiago was to go to the park and have a relaxing picnic lunch. (Birner \& Ward 1994)

(11) When I was six years old, I had to spend a night in the hospital, and I was terrified. (Ibid.)

Birner and Ward rejected the analysis of the definite article in terms of cognitive frames because "there is typically more than a single park within a given city" (Birner \& Ward 1994:99). However, in example (10), the use of the singular defi-

5 In this example, the definite the President can also be considered as an instance of a functional concept definite (Löbner 1985, 1998). 
nite in the park is felicitous, and in example (11), "there is no mention of a city that can give rise to a frame that might plausibly contain a hospital” (Ibid.:99). Epstein disagrees with Birner and Ward, explaining that the definite the park in examples such as (10) does represent a stereotypical element within the "city" frame; it is not important to identify the exact park where the speaker went. Epstein points out that "the availability of frame-knowledge is not dependent on explicit mention of the frame itself in the surrounding discourse"(Epstein 1999:128).

We agree with Epstein that a cognitive frame, regardless of whether it is explicitly mentioned, can be activated and used in a discourse. However, we will argue that his analysis of examples (10) and (11) utilizing the "city frame" needs to be modified.

\subsection{Abbott (2001)}

Abbott (2001) categorizes "configurational uses of nouns" (i. e., "non-unique definites" according to her terminology $\left.{ }^{6}\right)$ into six subcategories: "proprietary items," "traditionally unique items," "predicate nominals," "products of writing," "locations," and "types." In this paper, we will not examine each of the six subcategories individually for configurational uses of nouns. Abbott cites examples (12)-(15) as those of definites of "traditionally unique items."

(12) [Hotel concierge to guest, in a lobby with four elevators]

You're in Room 611. Take the elevator to the sixth floor and turn left.

(Birner \& Ward 1994)

(13) Switch the light on. (Löbner 1985)

(14) Your 10:00 appointment - a Mr. Johnson - said he'd be late because he had to stop at the bank first. (Birner \& Ward 1994) = (5)

(15) Kim spent the night in the hospital. (Abbott 2001)

Talking about example (12), Abbott argues, "for a long time after the invention of elevators, it must have been customary for buildings to have only one" elevator.

6 Some previous studies, including Abbott (2001), have often adopted the term "non-unique definites" to refer to definite descriptions whose referents cannot be uniquely identified by the interlocutor. However, we prefer the term "configurational uses of nouns," as used by Löbner (1985), or "definites in configurational use," because, as we will see later, the referent of a singular definite of this type will in fact be considered to be a unique element (or a unique role) within a cognitive frame. 
The same holds true for electric lights in example (13): it should be the case that there has always been only one electric light in a room. This explanation also holds true for the bank in example (14) and for the hospital in example (15). Abbott identifies such definites as "traditionally unique items." She confirms that her approach does not essentially contradict Epstein's frame analysis. The reason why Birner and Ward reject the frame analysis is that, nowadays, a city generally has many parks, many hospitals, etc. According to Abbott, however, the frame analysis is effective in the explanation of this phenomenon because "if we go back to when these usages were first being established, it may have been true that there was typically only one of these things per town, or at least one salient thing for any group of people."

\subsection{Löbner (1985, 1998)}

Löbner (1985) distinguishes three types of nouns: sortal, relational, and functional nouns. "Sortal nouns classify objects, whereas relational nouns describe objects as standing in a certain relation to others." "Functional nouns relate objects unambiguously (or one-to-one) to others," while "the referent (or value) of a functional noun depends, in general, on the situation referred to." This logical-semantic distinction of nouns is significant for the analysis of definites. According to Löbner (1985), "the meaning of the definite article consists in the indication that the noun is to be taken as a functional concept." Löbner (1998) also argues that "the head noun of an associative anaphora NP is taken as an FC2" (i. e., a functional concept that has both a situational and a possessor argument) and the FC2 interpretation of the head noun yields a one-to-one relation between the referent of the definite associative anaphora and the possessor (or the trigger), hence warranting the "uniqueness" of the referent. The relation between the referent of a definite associative anaphora and the possessor is based on general knowledge, or more specifically, the discourse referent network, which constitutes a "frame." Löbner's (1998) frame concept is inspired by Barsalou's frame, which we will examine later.

\subsection{Perspective}

Our fundamental claim concerning the singular definite is as follows: all singular definites are explained with the uniqueness theory, and even singular definites, which do not seem to have any uniquely identifiable referent (i. e., "non-unique 
definites" according to the terminology developed in some previous research), satisfy the uniqueness condition within a cognitive frame. However, we will argue that the cognitive frame involved in several examples such as the hospital or the bank in examples (5), (6), (11), and (15) above is not a fixed idea such as a "city" frame, as Epstein or Abbott claim. Birner and Ward observe that the singular definites in configurational use are generally used to refer to locations. We shall presently illustrate why singular definites of this type often - but not always - refer to locations.

The zero article plays a part in some varieties of English. We notice the frequent appearance of the word "hospital" without an article in British English, for instance, in expressions such as "in hospital, go to hospital, leave hospital, be taken to hospital, and be airlifted to hospital," whereas the definite article in American English is often retained in the same expressions, as in "in the hospital, go to the hospital, leave the hospital, be taken to the hospital, and be airlifted to the hospital." Our analysis of this point is founded on reflection about data derived from the American English style. Furthermore, as it has already been pointed out in some previous research, even in American English, bare nouns are used in several idioms such as "go to school" or "go to church." This paper, however, will not deal with the problem of bare nouns, but focus on the opposition of singular definites with singular indefinites.

\section{The unique role within a cognitive frame}

\subsection{Cognitive frame}

A cognitive frame is a network of knowledge that connects various events, situations, persons, objects, or their characters and the entire spectrum of relations among these elements. Cognitive frames were first conceived of by Minsky (1974, 1977) and Schank \& Abelson (1977) within the domain of artificial intelligence, and then applied to the domain of cognitive science. Our notion of cognitive frame is inspired by Fauconnier's $(1984,1994)$ mental space theory and Barsalou's (1992) frame theory. Barsalou's frames are based on an attribute-value structure, within which attributes are figuring in the scheme. Barsalou's "attribute" is equivalent to "dimension," "variable," "slot," or "role" under other theories. In this paper, we adopt the term "role." Barsalou also assumes that "frames are dynamic relational structures whose form is flexible and context dependent" (Barsalou 1992:21) 
and "frames can represent exemplars and propositions, prototypes and membership, subordinates and taxonomies" (Ibid.:21) as well as "conceptual combinations, event sequences, rules, and plans" (Ibid::21). We illustrate a simplified version of a cognitive frame for "wedding" in Figure 1.

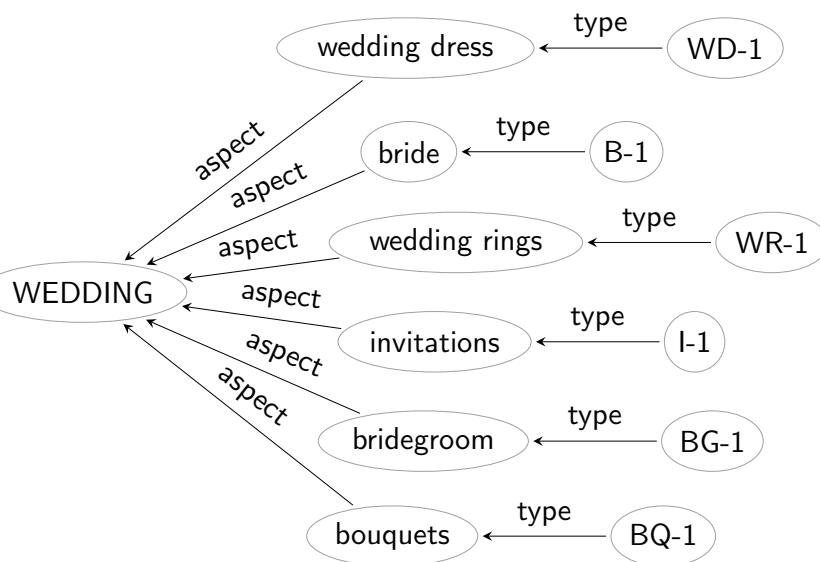

Figure 1: Wedding frame

As shown in Figure 1, the "wedding" frame has a central node labeled with "wedding," and nodes for each "role" (i. e., "attribute" according to Barsalou's terminology), more specifically, "bride" and "bridegroom," "wedding dress," "wedding rings," "bouquets," "invitations," and so forth, and nodes for its "value." The links between the central node and the nodes for roles are assigned general labels such as "aspect," and the links between the nodes for roles and those for values are assigned general labels such as "type." As Löbner (1998) notices, the roles figuring in cognitive frames are functional concepts. Thus, a cognitive frame, in the case of definite associative anaphoras, guarantees the connection between an anchor (which is represented by a central node) and its roles, hence warranting the use of a definite article for each role. Example (16) shows how the cognitive frame for "wedding" works in discourse.

(16) A : How are you?

B : I'm fine. And you? Have you already written the invitations? And have you thought about the bouquets?

A : Yes, but I haven't chosen the dress yet... 
B : Really? And the wedding rings? You've got them already?

A : Yes, Benjamin, he does everything very quickly.

Example (16) is a conversation between two friends, who met on the street, and one of whom would soon get married. Even if none of them referred to the context of a wedding, they could use definite descriptions such as the invitations, the bouquets, the dress, and the wedding rings at first mention. The use of these definites is possible because speaker B knew well about her friend's wedding and they had in common the cognitive frame for a wedding. When a wedding is presented explicitly or implicitly, the wedding frame is brought forth, and the roles that are a part of this frame are activated and ready to be mentioned with a definite article. Each role within a cognitive frame can correspond to various values, namely various individuals in the real world.

As Barsalou (1992) asserts, we share with each other both cognitive frames founded on an event or a situation, such as a "wedding" frame or an "anniversary" frame, and cognitive frames characterized by an individual or an object, such as the "house" frame, as illustrated in example (17).

(17) [An invited guest, to whom a couple is showing their new house, asks] Where is the kitchen?

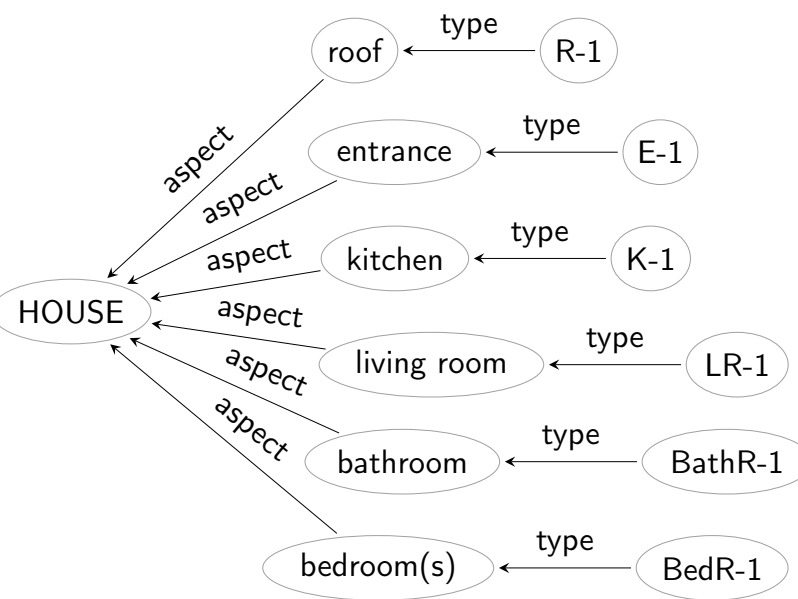

Figure 2: House frame 
In example (17), the guest can justly say the kitchen, using a definite article, at first mention, because as shown in Figure 2, the "house" frame contains as "roles" a roof, an entrance, a kitchen, a living room, a bathroom, (a) bedroom(s), and so forth. Hence, in a situation where the "house" frame is evoked or activated, we can employ a definite article without an explicit antecedent to mention the roles with an existential presupposition in the "house" frame.

It must also be mentioned that cognitive frames are culturally and socially defined, and the elements contained in a cognitive frame may vary across different cultures and languages and are subject to personal variations.

\subsection{Flexibility of cognitive frames: which of the cognitive frames is inferred?}

Singular definite descriptions without a unique referent explicitly introduced in the context (i. e., singular definites in configurational use) are considered to perform a unique role within a cognitive frame. The approach in terms of cognitive frames concerning this issue has already been adopted by Epstein and other researchers; however, we will propose another interpretation of cognitive frames for several instances that Epstein (1999) and Abbott (2001) have analyzed.

Compare examples (18), (19), and (20) to ascertain the cognitive frames that permit the use of the definite the hospital.

(18) In Paris, I caught the measles and I went to the hospital to receive treatment.

(19) [In Paris, a woman talks about her husband who is an engineer.] He is going $\left\{{ }^{*}\right.$ to the hospital/to a hospital\} to do some wiring.

(20) [In Paris: the words of a member of a movie camera crew] Last week, we went to $\left\{^{*}\right.$ the hospital/a hospital $\}$ to film a scene.

There are, of course, several hospitals in Paris. In example (18), the singular definite the hospital is quite appropriate, even though the hearer cannot identify the particular hospital in Paris where the speaker visited. In examples (19) and (20), too, the hearer is in no position to know which particular hospital is being talked about; however, the definite the hospital is no longer adequate, and the indefinite a hospital is obligatory instead. Where does this difference in the acceptability 
of the definite the hospital stem from? The answer lies in the different cognitive frames evoked in each example.

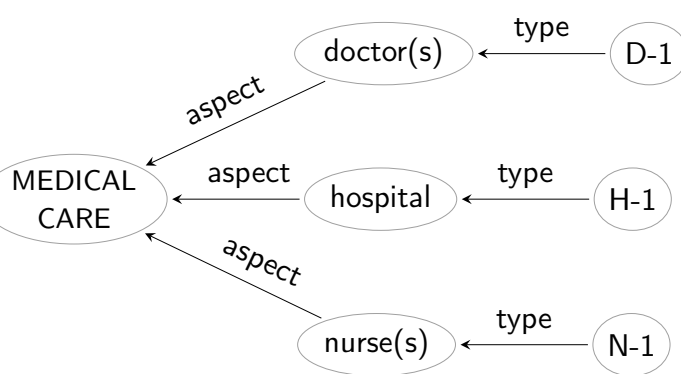

Figure 3: Medical care frame

In example (18), the context of "catching the measles" brings about a "medical care" frame, which includes "doctor(s)," "nurse(s)," "hospital," etc. In the context of this "medical care" frame, the hospital plays a unique role. On the other hand, in example (19), it is a "wiring" frame that is evoked, which comprises "wiring diagram," "screwdriver(s)," "plier(s)," etc., as stereotypical constituents; "hospital" does not figure in this frame. Similarly, in example (20), it is a "movie filming" frame that is called up, which has "director," "cameraperson(s)," "projector(s)," "scenario," "actor(s)," etc., as stereotypical roles, but not "hospital." In other words, there is no intrinsic relation between a hospital and a wiring repair job or the filming of a movie. That is why we cannot use the definite expression the hospital in examples (19) and (20). Hence, we may conclude that the cognitive frame supporting the felicitous use of the definite the hospital in example (18) is not a "city" frame but a "medical care" frame or a "surgery" frame, which involves "doctor(s)," "nurse(s)," "hospital," etc., as roles.

Now, let us compare example (21) with (22) and example (23) with (24). Suppose that, in the context of all these examples, there are several banks and swimming pools in the city where the speakers live.

(21) I'll stop at the bank to withdraw some money.

(22) I'll go \{*to the bank/to $a$ bank\} for a job interview.

(23) It's so hot out today! I'll go to the swimming pool this afternoon. 
(24) [on cell phone] Listen, my darling, I'm at work. I must go to deliver a pizza \{to *the swimming pool/to a swimming pool\} and I don't really have time to talk to you now...

In example (21), the speaker can use the definite description the bank without having a particular bank in mind, and it will not matter whether the hearer cannot identify the bank in question. Since the cognitive frame for "withdrawing money" typically includes "bank," "cash card," "ATM," etc., as constituent elements, the definite description the bank performs a unique role in this cognitive frame. In example (22), however, the use of the definite the bank is not appropriate if the hearer does not know exactly which bank the speaker is talking about; this is because the cognitive frame in question is that of "a job interview," and a job interview frame does not presume a "bank." That is why we use the indefinite a bank and not the bank. The same argument can be applied to examples (23) and (24). In example (23), the use of the definite the swimming pool is quite natural since the speaker is going to the pool to swim, and it is a perfectly acceptable usage even if the hearer does not know which particular swimming pool is being referred to, and even if the speaker himself/herself does not know which swimming pool he/she is going to. Since the cognitive frame for "swimming" typically contains a "swimming pool," the definite the swimming pool performs a unique role within this frame. On the other hand, if the speaker in example (24) is working in a pizzeria and if he/she is going to a swimming pool to deliver a pizza, he/she does not use the definite the swimming pool; instead, he/she uses the indefinite a swimming pool. A swimming pool is a place for people to swim, and it has nothing to do with the delivery of pizza. The context in example (24) calls up a cognitive frame for "delivery of pizza," and this frame does not have "swimming pool" as one of its typical elements; thus, the use of "swimming pool" with the definite article is unacceptable because "swimming pool" does not play a unique role.

Through comparing the given examples, we may reasonably conclude that the acceptability of configurational uses of nouns such as the hospital or the bank is not due to the "city" frame, as Epstein or Abbott claim, but owing to frames such as a "medical care" frame, which contains "hospital" as a unique role, or a "withdrawing money" frame, which contains "bank" as a unique element. 


\subsection{Location nouns}

Birner \& Ward (1994) observe that definite descriptions in configurational use with singular countable head nouns are generally used in references to locations ${ }^{7}$, and Abbott (2001) agrees. Nevertheless, Epstein (1999) disagrees, and so do we. Indeed, most of the definites in configurational use in the examples that we have examined thus far are location nouns such as "hospital," "bank," and "swimming pool." This is because locations such as hospitals, banks, swimming pools, post offices, cinemas, and pharmacies are part of the services we seek in everyday life, and consequently, these locations are quite naturally connected to the cognitive frames that are recalled when these services are mentioned or suggested. For instance, in banks, we deposit or withdraw money; we go to the swimming pool for a swim, not for the delivery of a pizza. In hospitals, we undergo medical treatment or an operation or we may visit someone there. People, in general, do not go to a hospital to repair wires or to film movie scenes. Similarly, our usual activity in post offices is to buy stamps and send letters or parcels. In other words, information about the relation between these locations and their utilities is constructed and crystallized in the form of knowledge networks, otherwise known as cognitive frames. That is why locations are quite likely to figure as stereotypical elements and function in unique ways within cognitive frames. ${ }^{8}$ Another reason why definites in configurational use frequently represent locations is that information concerning a location appears, in many cases, in the background of a discourse, but rarely as its theme. That is, the identification of the location is not necessarily essential in the discourse concerned. The configurational use of nouns is acceptable only when there is no necessity to identify the referent of this definite in the discourse in question (cf. Birner \& $\left.\mathrm{Ward}^{9}\right)$. This is because

7 Birner \& Ward (1994) maintain that non-unique definite descriptions ("definite descriptions in configurational use" or "configurational uses of nouns" in our terms) generally occur with one of the following three types of nouns: mass nouns (the milk), plural nouns (e.g., Pass the rolls), and location nouns.

8 It is plausible to assume that a location noun by itself can evoke some cognitive frame. However, it is not the simple use of a location noun that permits the employment of a definite article with this location noun. For example, in example (20), we may suppose that the noun "hospital" evokes a "hospital" frame, but this is not the frame where the referent of the hospital is to be anchored to; the entire context in example (20) triggers off a "movie filming" frame, and therefore, the definite the hospital is irrelevant. The use of the definite the hospital inevitably needs to be anchored in a cognitive frame that is related to the functions of a hospital.

9 We do not agree with Birner \& Ward (1994) that the uniqueness condition cannot account for all uses of the singular definite article. Nevertheless, Birner and Ward appropriately claim that 
a role within a cognitive frame must be an element that is neither differentiated nor individualized in context: a "role" should be able to take different values in the real world; therefrom, its name "role" originated.

Now, consider another set of examples involving location nouns. Examples (25) and (26) describe a scene wherein one person calls up his friend's cell phone. The caller asks his/her friend about his/her whereabouts, and the friend answers him/her. We may suppose that there are many hospitals in the city where these two people live.

a. I'm in the hospital. / I'm at the hospital.

b. I'm in a hospital. / I'm at a hospital.

a. *I'm in front of the hospital.

b. I'm in front of a hospital.

It is possible to use a definite article in "I'm in the hospital," as shown in example $(25)^{10}$, even if the hearer cannot identify the particular hospital in question. In example (26), however, if the hearer is not in a position to identify the hospital in question, it is unacceptable to employ a definite article, as in "I'm in front of the hospital"; instead, we use an indefinite article and say "I'm in front of a hospital." What, then, is the basis for such a usage?

Note that there are certain nuanced differences in example (25) between the usage of the definite article, as in (25a) "I'm in the hospital," and the usage of an indefinite article, as in (25b) "I'm in a hospital." The use of the definite the hospital implies that the speaker is in a hospital to receive medical treatment or consult a doctor (in "I'm in the hospital") or to visit someone who has been hospitalized (in "I'm at the hospital"). There are no such implications in the use of the indefinite $a$ hospital. The utterance "I'm in a hospital" simply means that the speaker is in a hospital for a reason that has no relation to the function of a hospital-to deliver flowers, perhaps, or to repair elevators. We are fairly certain that the use of the definite the hospital triggers a cognitive frame that inevitably implies elements

\footnotetext{
"whenever the referent is not uniquely identifiable on the basis of the definite NP, it must be both undifferentiated and not relevantly differentiable in context." (Birner \& Ward 1994)

10 The interpretation of example (25a) varies depending on whether "in" or "at" is used. The utterance "I'm in the hospital" implies that the speaker is in the hospital as a patient to receive medical treatment, while the utterance "I'm at the hospital" means that the speaker is at the hospital as a visitor: he/she is visiting someone who has been hospitalized.
} 
such as "consultation," "medical treatment," "operation," or "visit to a sick person." On the other hand, the act of being in front of a hospital in example (26) hardly evokes the functions that are attributable to a hospital. If someone is inside a hospital, we are more liable to imagine that the person is there to receive medical care or to visit a sick friend. But if someone is in front of a hospital, we do not necessarily infer that this person is on his/her way to consult a doctor. That is why no cognitive frame that contains "hospital" is activated to permit the use of the definite the hospital in example (26). These pieces of data demonstrate that the appropriateness of the definite the hospital in configurational use depends not on whether the definite designates a location, but on whether the definite is used in a context in which an appropriate cognitive frame with "hospital" is evoked.

We will now present obvious examples to demonstrate that singular definites in configurational use are not limited to location nouns.

(27) No problem, I'll get the maid to do it. (Epstein 1999)

(28) Waiter, I demand to see the menu! (Ibid.)

(29) A : I'd like a cappuccino, but I don't know if they have it...

$\mathrm{B}$ : You have only to ask the waiter.

(30) A : I'd like a cappuccino, but I don't know if they have it...

$\mathrm{B}:$ *You have only to ask the waiter with blue eyes.

As Epstein (1999) explains, the sentence in example (27) with the singular definite the maid may be used either in a hotel or in a home where there are several maids; he argues, "(28) would be felicitous in a situation where both the speaker and the waiter can see an entire stack of menus on the counter." Similarly, the use of the singular definite the waiter in example (29) is quite natural even if there are several waiters working in this café at the moment of utterance. However, none of these definites in configurational use refers to a location. The acceptability of the definites the menu and the waiter is explained both by attributing it to the presence of some cognitive frames such as an "order in a café" frame, which includes "menu" and "waiter" as a unique role, and by attributing it to the fact that these definites are elements that are neither relevantly differentiated nor individualized in context. Therefore, the use of the definite "the waiter with blue eyes" in example (30) is not adequate as a configurational use of nouns. 
There is another well-known type of definite in configurational use that does not designate a location.

(31) He tripped on the leg of the chair.

(32) After landing, I got on the wing of the plane and looked up to the sky.

In general, a chair has four legs and a plane has two wings, and yet, the use of the singular definite article for the head noun in the leg of the chair or the wing of the plane is not paradoxical in the examples above. As Löbner (1998) and Barker (2005) notice, possessive definite descriptions can be quite often used "in contexts in which more than one object satisfies the content of the description" (Barker 2005). Barker refers to this type of possessive definite description as a "possessive weak definite." Namely, possessive weak definites belong among the definites in configurational use that we have discussed thus far. Since the problem of possessive weak definites has been fully discussed in previous research like by Löbner (1985, 1998) and Barker (2005), we will not go too far into this matter here, but we would simply point out that as shown in examples (31) and (32), there are many instances of possessive weak definites, that is, possessive definite descriptions in configurational use, that do not refer to locations.

\subsection{Definite associative anaphora}

It is quite evident that there is a certain affinity between the definite in configurational use and the definite associative anaphora, because both definites have relevance to some cognitive frame. In this section, we will illustrate their resemblance in addition to a slight difference between them.

The configurational use of definite descriptions is felicitous when the noun functions as a unique role within a certain cognitive frame, which is activated by the linguistic context or the immediate situation. There are occasions when an anterior context explicitly introduces some cognitive frame or others with a linguistic expression, but it is not always the case. Even without any obvious expression that triggers a cognitive frame, we employ a singular definite description when the hearer is supposed to (re)construct the cognitive frame in question that has a particular noun with a unique role. Examples (33) and (34) report the utterances of a man who has arrived late for his appointment and is offering an excuse after a brief greeting. 
(33) I'm sorry, but \{the bus/the taxi\} had engine trouble.

(34) I'm sorry, my car sideswiped $\left\{{ }^{*}\right.$ the bus $/{ }^{*}$ the taxi/a bus/a taxi\}.

While offering an excuse for being late, the speaker in example (33) may use the definite the bus or the taxi, whereas the speaker in example (34) uses the indefinite a bus or a taxi. Where does this difference in acceptability of the definite description come from? Our explanation is as follows: if someone arrives behind schedule, out of breath, and mentions "the bus" or "the taxi," the situation forces us to interpret this bus or this taxi as the bus or the taxi that the speaker took. It means that the hearer in example (33) reconstructs a cognitive frame of "traffic" or "transportation" containing "a bus" or "a taxi" as a unique role. The bus or the taxi that the speaker had employed in reality corresponds to the bus or the taxi that exists within this cognitive frame. On the other hand, there is nothing in example (34) that activates a cognitive frame of "traffic" or "transportation" involving a bus or a taxi as a unique role, which would surely bring about a minor collision. In other words, when we drive a car, we do not necessarily have an accident with a car or a taxi. Therefore, there is no existential presupposition of a unique bus or taxi playing a role within a cognitive frame; the speaker thus inevitably uses an indefinite description, "a bus” or "a taxi." Reconsider examples (33) and (34) from a different viewpoint. In example (34), if the speaker uses a definite description such as the bus or the taxi, saying "I'm sorry, my car sideswiped the bus" or "I'm sorry, my car sideswiped the taxi," the hearer will ask him "Which bus?" or "Which taxi?" On the other hand, even though the speaker uses the definite the bus or the taxi, the hearer in example (33) will not pose this question because the definite the bus or the taxi indeed functions as a unique role within the cognitive frame. This fact shows, again, that the singular definite description as a unique role within a frame is employed in a context where the identity of the referent does not come into question.

As Du Bois (1980), Löbner (1985), Epstein (1999), and others have noted, the mechanism of the uniqueness of an element in a frame resembles the mechanism of associative anaphora. Consider examples (35), (36), and (37).

(35) I caught a taxi in front of the library. The driver was very friendly.

(36) I am terribly afraid of going to the dentist. The drill terrifies me...

(37) I tried to hang myself... but the chair didn't want to fall. 


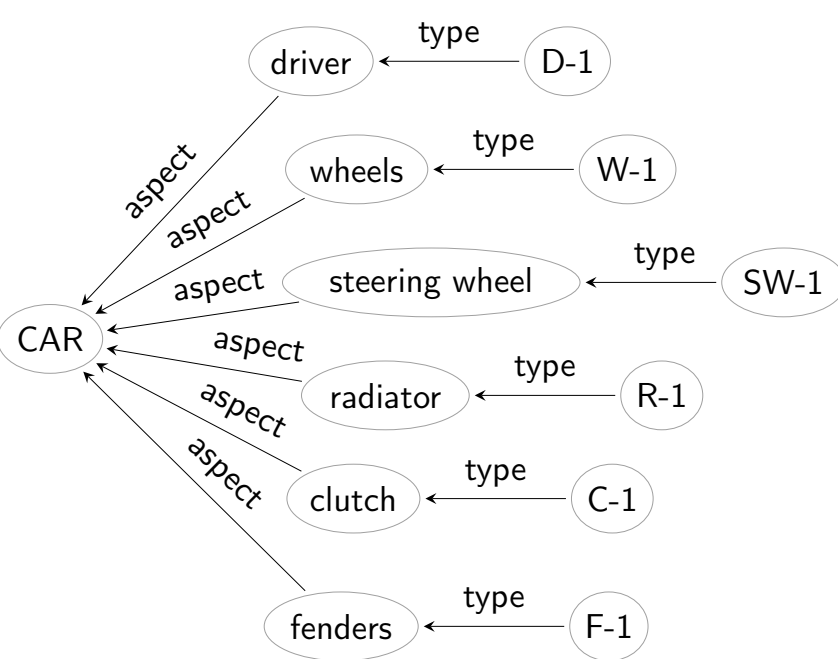

Figure 4: Car frame

In associative anaphora, the anaphoric relation between the antecedent and the anaphoric expression is frequently established by some cognitive frame. In the cognitive frame of "taxi" or "car," shown in Figure 4, we can evoke elements such as "driver," "steering wheel," "radiator," and "clutch," and this "car" frame in example (35) permits the associative anaphora between "a taxi" and "the driver." The anaphoric relation in example (36) between "the dentist" and "the drill" is founded in a "dentist" frame, which includes elements such as "assistant(s)," "chair," and "drill." The anaphoric relation in example (37) between the contextual antecedent hang oneself and its anaphoric expression "the chair" is also guaranteed by the cognitive frame of "suicide by hanging oneself," which contains "rope" and "chair" as stereotypical components. In these three examples concerning definite associative anaphora, it is a cognitive frame that appeared in the previous context that connects the antecedent with its anaphoric expression. In the case of the configurational uses of definite descriptions, there is no antecedent or no cognitive frame introduced explicitly in the discourse, but the definite in configurational use performs a unique role in some cognitive frames that are supported by the situation of utterance. Even if there is no explicit antecedent or no expression introducing a cognitive frame, the configurational use of nouns is validated through the same mechanism as in the case of associative anaphora. 


\section{Conclusion}

In this paper, we have demonstrated that the use of definite descriptions, which has been considered by some researchers to be highly resistant to any explanation with the uniqueness theory, stems from certain unique roles within cognitive frames evoked by linguistic contexts, circumstances of utterances, or the immediate situation. Epstein (1999) has already adopted the frame approach in his analysis of the definite, but it seems to us that there is a misunderstanding about the nature of a cognitive frame for the configurational use of some definites such as the hospital or the bank. We have argued that the cognitive frame supporting the acceptable use of the definite the hospital is not the "city" frame but a "medical care" frame, or a "visit to a sick person" frame, and so forth. The definites in configurational use often - but not always - refers to a location, as previous researchers have noticed, and we have explained the reason for this high frequency of location nouns in definites of this type: locations such as hospitals, banks, and post offices are related with the services we seek in our daily life; the general use of common services creates certain cognitive frames and typical roles associated with these frames, which supports the configurational uses of nouns.

One of the most essential characteristics of the definite description is that it represents a referent that can be uniquely determined either on the basis of a cognitive frame, on the basis of a discourse domain, or by shared knowledge. Some previous studies on this subject have devoted too much attention to the identification of the referent in reality. However, what is important in the study of the definite description is not to identify the referent in reality, but to discover the cognitive frame, the discourse domain, or the shared knowledge on which the interpretation of the definite description is founded. In the configurational uses of definite descriptions, it is a cognitive frame or knowledge network that serves as the primary domain for possible interpretations of the definite description. 


\section{References}

Abbott, B. 1999. Support for a unique theory of definite descriptions. In T. Matthews \& D. Strolovitch (eds.), Proceedings from Semantics and Linguistic Theory IX, 1-15. Ithaca: Cornell University.

Abbott, B. 2001. Definiteness and identification in English. In N. T. Enikö (ed.), Pragmatics in 2000: Selected Papers from the 7th International Pragmatics Conference, Vol. 2, 1-15. Antwerp: International Pragmatics Association.

Abbott, B. 2006. Definite and indefinite. In K. Brown (ed.), The Encyclopedia of Language and Linguistics, 2nd ed., Vol. 3, 392-399. Oxford: Elsevier.

Barker, C. 2005. Possessive weak definites. In J.-Y. Kim, Y. Lander \& B. H. Partee (eds.), Possessives and Beyond: Semantics and Syntax, 89-113. Amherst, MA: GLSA Publications.

Barsalou, L. 1992. Frames, concepts, and conceptual fields. In A. Lehrer \& E. F. Kittay (eds.), Frames, Fields, and Contrasts: New Essays in Semantic and Lexical Organization, 21-74. Hillsdale, NJ: Lawrence Erlbaum Associates.

Birner, B. \& G. Ward, 1994. Uniqueness, familiarity, and the definite article in English. BLS 20, 93-102.

Christophersen, P. 1939. The Articles: A Study of their Theory and Use in English. Copenhagen: Munksgaard.

Du Bois, J. W. 1980. Beyond definiteness: the trace of identity in discourse. In W. L. Chafe (ed.), The Pear Stories. Cognitive, Cultural, and Linguistic Aspects of Narrative Production, 203-74. Norwood: Ablex.

Ducrot, O. 1972. Dire et ne pas dire. Paris: Hermann.

Epstein, R. 1998. Reference and definite referring expressions. Pragmatics and Cognition 6 (1/2), 189-207.

Epstein, R. 1999. Roles and non-unique definites. BLS 25. 122-133.

Fauconnier, G. 1984. Espaces mentaux. Paris: Les éditions du Minuit.

Fauconnier, G. 1994. Mental Spaces: Aspects of Meaning Construction in Natural Language. Cambridge: Cambridge University Press.

Gundel, J. K., N. Hedberg \& R. Zacharski 1993. Cognitive status and the form of referring expressions in discourse. Language 69. 274-307.

Gundel, J. K., N. Hedberg \& R. Zacharski 2001. Definite descriptions and cognitive status in English: why accommodation is unnecessary. English Language and Linguistics 5-2. 273-295. 


\section{References}

Hawkins, J. A. 1978. Definiteness and Indefiniteness: A Study in Reference and Grammaticality Prediction. London: Croom Helm.

Heim, I. 1983. File change semantics and the familiarity theory of definiteness. In R. Bäuerle, Ch. Schwarze \& A. von Stechow (eds.), Meaning, Use, and Interpretation of Language, 164-189. New York: Walter de Gruyter.

Kadmon, N. 1990. Uniqueness. Linguistics and Philosophy 13. 273-324.

Karttunen, L. 1976. Discourse referents. In J. D. McCawley (ed.), Syntax and Semantics 7: Notes from the Linguistic Underground, 363-386. New York: Academic Press.

Lambrecht, K. 1994. Information Structure and Sentence Form: Topic, Focus, and the Mental Representations of Discourse Referents. Cambridge: Cambridge University Press.

Löbner, S. 1985. Definites. Fournal of Semantics 4, 279-326.

Löbner, S. 1998. Definite associative anaphora. In S. Botley (ed.), Approaches to discourse anaphora: proceedings of DAARC96 - Discourse anaphora and Resolution Colloquium. UCREL Technical Papers Series, Vol. 8. Lancaster University.

Minsky, M. 1977. Frame-system theory. In P. N. Johnson-Laird \& P. C. Wason (eds.), Thinking. Reading in Cognitive Science, 355-376. Cambridge: Cambridge University Press.

Récanati, F. 1996. Domains of discourse. Linguistics and Philosophy 19, 445-475.

Russell, B. 1905. On denoting. Mind 14, 479-493.

Schank, R. C. \& R. P. Abelson 1977. Scripts, plans and knowledge. In P. N. JohnsonLaird \& P. C. Wason (eds.), Thinking. Reading in Cognitive Science, 421-432. Cambridge: Cambridge University Press.

\section{Author}

Ryo ODA

Kwansei Gakuin University

ryocat@hotmail.com 
